published in International Journal of Qualitative Studies in Education 2011 this version: final editorial changes not yet made

\title{
Interviewing Objects: Including Educational Technologies as Qualitative Research Participants
}

\author{
Catherine Adams \\ Department of Secondary Education \\ University of Alberta \\ Terrie Lynn Thompson \\ Department of Educational Policy Studies \\ University of Alberta
}

\begin{abstract}
This paper argues the importance of including significant technologies-in-use as key qualitative research participants when studying today's digitally-enhanced learning environments. We gather a set of eight heuristics to assist qualitative researchers in "interviewing" technologies-in-use (or other relevant objects) drawing on concrete examples from our own qualitative research projects. Our discussion is informed by Actor-NetworkTheory and hermeneutic phenomenology, as well as by the literatures of techno-science, media ecology, and the philosophy of technology.
\end{abstract}

For many people, life today is intimately intertwined with, mediated by, and at times surrendered to the everyday things of our world: cars and credit cards, emails and iPods, cups and keys. Educational activities and practices are similarly caught up in, tethered to, and shaped by the artefacts at hand: blackboards and books, passwords and online profiles, PowerPoint and plagiarism software. Yet for the most part, things are overlooked as incidental or inconsequential entities rather than problematized and enlisted as important participants in qualitative research projects. This is hardly surprising. Commonsense grants little or no agency to inanimate objects, a belief neatly encapsulated by the NRA bumper slogan: “guns don't kill people, people do.” However, our technology-saturated world is contesting this naïve severing of intention from nonhuman entities, and asks instead that we re-examine the complexity of human-technology relations. As Bruno Latour (1999) contends, it is neither the person nor the gun that kills, but the "citizen-gun" or "gun-citizen", a complex human-technology hybrid that, when 
assembled, necessarily engages new intentions, associations and actions. Moreover, such “imbroglios of humans and nonhumans are becoming increasingly part of our everyday life" (Michael 2000, 25) and, we add, educational environments.

Recognizing technologies-in-use as agential in shaping the existential and hermeneutic conditions of our lifeworld suggests educational researchers may be obliged to consider such technologies as relevant research participants. Given an artefact may be exercising a non-neutral influence over us - encouraging, discouraging, inciting or even coaxing the one who grasps hold of it to participate in the world in prescribed and circumscribed ways - then, as qualitative researchers, we might want to account for the shades and spectrums of such influences. Too, human-technology relations are not unidirectional: we simultaneously interpret, manipulate, adapt, use and even abuse artefacts in the service of our own intentions and ends. In an effort to bring to critical inquiry the information and communication technologies (ICTs) informing and reforming today's teaching and learning practices, we explore the inclusion of technologies-in-use as key qualitative research participants. We wonder: how we might begin to "trace the contingent simultaneity of intentions, decisions, affordances, interpretations, uses, codes, programmes...to reveal the nexus that co-constitutes the ethico-political site of technology" (Introna 2007, 22), and in particular, the host of digital technologies ${ }^{1}$ currently being taken up and used in learning contexts.

\footnotetext{
${ }^{1}$ This article is specifically addressing digital (computer-based) technologies, including web technologies, ICTs, presentation software (e.g. PowerPoint), and new media learning objects; technologies which may contribute to the creation of more digitally enhanced learning environments. However, we believe it is reasonable to apply our heuristics to a full range of teaching and learning technologies and artefacts, from Froebel's gifts to Interactive WhiteBoards. Technology, artefact, object, and thing are used interchangeably here, although we recognize that some philosophers may draw careful metaphysical distinctions between these terms.
} 
This re-consideration of technology mediated learning environments entails asking: How might a qualitative researcher "interview" a technology in an effort to disclose its material agency in co-constituting teaching-learning worlds? Expanding the notion of what it means to interview a research participant, we refer to the etymological origins of the word "interview". It is derived from the Old French verbal noun s'entrevoir, composed of two parts: entre-, meaning mutual or between, and voir, to see, which together mean "to see each other, visit each other briefly, have a glimpse of." Thus to "interview an educational artefact", is to catch insightful glimpses of the artefact in action, as it performs and mediates the gestures and understandings of its employer, involved others, and associations with other objects in the pedagogical environment.

The aim of this article is twofold. First, we explore the importance of including significant technologies-in-use as key participants when studying today’s digitallyenhanced learning environments: educational sites (both formal and informal) mediated through, by and with ICTs. Second, we outline eight heuristics which qualitative researchers might try when "interviewing" objects: following the actors, attending to the invitational quality of things, discerning the spectrum of human-technology relations, recognizing the amplification/reduction structure of such relations, applying McLuhans' laws of media, looking for breakdowns or accidents, untangling tensions, and constructing co(a)gents. We view heuristics as problem-solving techniques employed as "starting point[s] for further experimentation or refinement" ("Heuristic Methods" n.d., para. 17). These rules-of-thumb are not intended as prescriptive methods, but are offered as possible approaches to inquiry based on our own experiences using hermeneutic 
phenomenology (Adams) and Actor-Network Theory (Thompson) respectively to explore the involvements of particular technologies-in-use in educational environments.

The eight heuristics presented here thus emanate from two divergent theoretical and philosophical realms, and so may not all be applicable in a single study. In this regard, we suggest educational researchers consider possible misalignments with their own epistemological commitments. But further, if we recognize, with critical media theorist Mark Hansen, that new media technologies are "poised on the cusp between phenomenology and materiality" and as such have introduced "a theoretical oscillation that promises to displace the empirical-transcendental divide" (Hansen 2006, 297) structuring western thinking, it becomes clearer that both phenomenology and ANT are uniquely positioned to explore complementary facets of this unstable human-technology apartheid. Indeed, some philosophers of technology have recently begun to scope important intersections and overlaps between these two modes of inquiry (Crease et al. 2003, Introna 2007, Harman 2009, Verbeek 2005).

In gathering a set of heuristics to assist researchers in interviewing ICTs, we draw on concrete examples from our own qualitative research projects. We are not presenting research findings per se but rather, are using examples from our own research projects to illustrate how we employed particular heuristics to facilitate "interviewing" digital technologies in different learning contexts. Adams, in her efforts to describe teachers' and students' prereflective involvements with new media technologies, has conducted hermeneutic phenomenological research in technology-enhanced post-secondary classrooms (Adams 2006, 2008, 2010) as well as online learning environments (van Manen and Adams 2009). In a study examining teachers' lived experiences of teaching 
with PowerPoint, for example, Adams (2010) showed how PowerPoint slide presentation, regardless of the kind of knowledge it is serving to frame, exercises a powerful sway over the teacher in the moments of teaching, at times appearing as impenetrable obstacle, rather than a generative support to the teacher desiring to pursue her pedagogical sense of tact. Beyond gathering and analyzing data via a usual set of human science research techniques - classroom observation, phenomenological interviews of teachers and students, and self-reflective journals (van Manen, 1997) —Adams employs a variety of analytical devices and methodological heuristics aimed at revealing the mediating influences of the given technologies in play. These heuristics are gleaned from several interdisciplinary sources, each bearing explicit philosophical and theoretical ties to phenomenology or post-phenomenology: philosophy of technology, human environmental aesthetics and critical media studies.

Thompson is investigating informal work-learning activities in online communities using ANT to help examine how working adults are re-negotiating the social and material aspects of work-learning spaces online, to explore how work-related learning is enacted in online communities, and to study the implications of the intertwining of people and objects in multiple, fluid and distributed actor-networks (Thompson 2010a, 2010b). In this study, online communities can describe a gathering of people online that is organic and driven by a shared interest or need (i.e., Boyd 2006). These kinds of spaces may also be purposefully nurtured by professional associations, workplaces, or businesses. This research project focuses on these spaces—outside the auspices of formal online courses. The technologies used in the online communities explored in this study were diverse and included ListServs, discussion boards and forums, 
Yahoo groups, e-mail, blogs, RSS feeds, or popular social networking sites such as

Facebook or LinkedIn. The human participants in this study were 11 own-account selfemployed workers (contractors and consultants without staff). Semi-structured interviews were conducted, with follow up dialogue, either by e-mail and/or short conversations, providing additional data.

ANT has proved successful in documenting human-technology interactions in the domain of science studies, and has been adopted in fields such as medicine (Mol 2002), public health (Singleton 2005), literacy (Leander and Lovvorn 2006) and management (Neyland 2006). Meanwhile, phenomenology has been providing major contributions to philosophy of technology since the latter's inception as a field of studies (Ihde 2004, Mitcham 1994). Hermeneutic phenomenology has lent important insight to pedagogical studies, notably Max van Manen $(1997,2002)$. Extending this work in light of $21^{\text {st }}$ century educational environments is imperative.

\section{Theoretical Framework}

The eight heuristics in this paper were derived from philosophical insights of phenomenologists, as well as conceptual understandings given by Actor-Network Theorists. Several of the methods used were explicitly suggested in the literature. We begin with a brief introduction to the ways that objects or things are conceived in the two primary research frameworks - ANT and phenomenology — and then highlight notable connections and disconnections. 


\section{Phenomenology}

Phenomenology $y^{2}$ is both a philosophical orientation and a means of human science inquiry. The clarion call of phenomenology, "back to the things themselves" ( $Z u$ den Sachen selbst), encapsulates this philosophy's plea to revive living contact with the world, and to return to concrete, lived human experience in all its variegated richness. As an approach to research in education, phenomenology involves a careful and systematic reflection on the lived experience of pedagogical phenomenon. The term lived experience has special methodological significance for phenomenology and refers to "our immediate, pre-reflective consciousness of life" (van Manen, 1997). As such, phenomenological inquiry is oriented to the lifeworld as we immediately experience itpre-reflectively, pre-verbally, pre-theoretically—as teachers, students, children or parents. The approach is guided by philosophical phenomenological methodology and augmented by human science techniques and procedures.

Our everyday, primordial involvements with the material conditions of our world figure prominently in phenomenological description and reflection. Phenomenologically speaking,

Things pack and harass [human] existence in a variety of ways which determine the spectrum of not only bodily, but also spiritual, feelings and emotions. Things cheer, entertain, satisfy. Things intimidate, scare, hamper. Things embarrass. Things depress. Things transform. Things escape. Things challenge and defy. Things embroider existence and make it empty. (Benso 2000, 144)

\footnotetext{
${ }^{2}$ For a more substantive description of phenomenology as a qualitative research methodology in education, along with a brief account of its philosophical roots, please see Adams and van Manen (2008), or van Manen and Adams (2010).
} 
From the handiness of Martin Heidegger's hammer, to the focal practices gathering around Albert Borgmann's warm hearth, from Maurice Merleau-Ponty’s knowing typing hands, to the surgical sensitivity of Don Ihde's dental probe, phenomenology has been serving to disclose and adumbrate our primal, pre-reflective, corporeal involvements with the everyday things of our lifeworld.

Merleau-Ponty $(1962,143)$ observes "our existence changes with the appropriation of a fresh instrument". Phenomenology seeks to describe the structures of this existential change experience. As educators, we may begin to wonder then what transformations of perception, what translations of action, are occurring-for teachers and students alike - each time we take up a "fresh instrument" in the lived space of the classroom. For example, in seizing hold of PowerPoint, a teacher is not only aided, enmeshed, and constrained by the designs of its software script, the teacher is also surrendered to the language, imagery, framing, at-handedness, sensuality, and mediation of its symbolism and materiality. A PowerPoint presentation is "never merely a visual object...nor is it a mere tissue of functions" (Jager 1985, 222), rather it is inhabited by student and teacher alike (Adams 2010). As teachers become more informed about the affordances, and skilled in the use of ICTs these same technologies are always already re/de/informing their perceptions and actions in the world.

\section{Actor-Network-Theory}

Actor Network Theory (ANT) is a unique collection of relational and material understandings, concerned with associations between human and non-human actants in day-to-day practices. Although ANT is described as a theory, approach, method, sensibility, and/or toolkit, it clearly advocates that object and human actants should be 
placed on an equal analytic level. Thus, both people and objects are legitimate research participants. Actants (human and non-human) are co-constituted in webs of relations with other actants. As an object-oriented philosophy, ANT maintains that an object is what it is because of the retinue of relations in which it is entangled. Actor-networks are thus comprised of actants that become involved in ensembles. It is because of these ties that an actor-network exists. Callon $(1987,93)$ explains that "an actor-network is simultaneously an actor whose activity is networking heterogeneous elements and a network that is able to redefine and transform what it is made of " (emphasis added).

Relations are paramount. Yet, being interconnected is not enough. ANT is interested in how alliances come to be and how actants end up juxtaposed with others. Through this ongoing work of (re/dis)assembly, Latour (1988) argues, both human and non-human actors create new sources of power and legitimacy as they renegotiate who is acting in the world, who matters, and who wants what. Although ANT has been used widely in other disciplines, it is just making an entrée into education and learning. Emerging from the Science, Technology and Society (STS) field, ANT has utility for educational research. As Scott Waltz $(2004,158)$ argues, "things do not play a role in an educational setting by acting apart from us ... rather they interact with us as surprising cocreators of educational environments".

\section{Connections and Disconnects}

As a qualitative research methodology, phenomenology aims to describe and reflect on our prereflective experiences - here, with the things and technologies of our teaching and learning lifeworlds. ANT amends this project, seeking to unravel the alliances and practices that come to be (re/dis)assembled in networks as humans and 
technologies engage with each other. There are, of course, substantive differences between these two perspectives. For example, the focal point of analysis in ANT is the actor-network comprised of both humans and non-humans; whereas phenomenology reflects on the prereflective experience of the human being intentionally oriented and intimately involved in their lifeworld. While both forms of inquiry attempt to do away with the subject-object dichotomy, Verbeek $(2005,166)$ explains that they do so in different ways: Latour (1993) denies that the gap exists and instead emphasizes hybrid or quasi-objects and quasi-subjects, while phenomenology tends to highlight the "mutual engagements that constitute subject and object". The methodological characteristics of each research approach spring from different roots: ethnomethodology (ANT) vs. phenomenology. These differences of origin and focus are evident in the superficially subtle but nonetheless significant distinctions in vocabularies, for example, materialsemiotic vs. hermeneutic-phenomenological.

Despite these differences, a number of theoretical and methodological overlaps are evident. Indeed, philosopher Graham Harman $(2009,100)$ claims that "phenomenology harbors resources that lead it to converge with Latour's insights, however different their starting points may be." He $(2009,143)$ explains how both shy away from thinking about things as solid objects and instead as regard them as "a system of things in reciprocal connection", aka the network and Heidegger's equipment. Both ANT and phenomenology talk about the human and the technological in a single, hyphenated breath, aspiring to dissolve out-worn subject-object dichotomies. Both recognize human-technology relations as co-constitutive - the things of our world constitute us as much as we constitute them. Both ANT and phenomenology privilege 
description over explanation and theory. Both reject the application of some "all-purpose, all-terrain 'methodology"” (Latour 2005, 96n126), preferring instead a heuristic toolkit of possible approaches to be adapted in the field. Finally, both have a primary interest in letting the things of the world speak for themselves (Heidegger 1962).

\section{The Eight Heuristics}

We now turn to a discussion of eight heuristics to assist qualitative researchers wishing to query the things and objects - the technologies-in-use - that may be holding sway in different educational environments. Each heuristic is informed by ANT or phenomenology literature, as well as our own field research. The first two heuristics build on key philosophical tenets in ANT and phenomenology. These two heuristicsfollowing the actors (ANT) and listening for the "invitational" quality of things (phenomenology) — set the stage by opening up possibilities for exploring human and technology inter-relations, albeit in two distinctive ways. The next six heuristics then delve deeper into other conceptual tools that researchers may draw on when “interviewing" objects. Heuristics three, four, and five are framed by phenomenological insights in order to explore different ways of uncovering human-technology interactions. Heuristics six, seven, and eight draw on ANT provide another set of conceptual tools to examine the socio-materiality of human-object relations. Once more, we are not attempting to reconcile the phenomenological and ANT-derived heuristics here and readers may discern some overlaps, compatibilities, and contradictions. 


\section{Heuristic 1: Following the Actors}

This heuristic derives from the popular ANT imperative to "follow the actors". Harman's $(2007,44)$ analogy is apt: "we cannot discover the nature of a thing by looking into its heart, but must follow the blood that circulates from that thing through all its arteries and far-flung capillaries". The point is not to create an exhaustive list of all possible entities in an actor-network but rather to look for "mediators making other mediators do things", human or non-human (Latour 2005, 217). As one follows the actors, it is important to attend to what is being mobilized (knowledge, beliefs, or actions) in the shifting spaces created by the inter-actions between actors.

The delete button is an interesting actor-network to unravel. As Aanestad (2003) explains, the capacity for action is relational, dynamic and collective rather than embedded in particular network elements. Elements achieve their form and character in relation to the others (Law 2008). The delete button seems to be an important actant. It was a prominent object in the accounts of self-employed workers' inter-actions with others in cyberspace collectives. Moreover, it is connected to both human and non-human actants and enmeshed in an array of relations. It is a key pressed when one wants get on with things. Yet, it is more than a tool. When we accept its invitation, we enter into a socio-material assemblage: we are "deleting" and we could not do this without our delete button.

Attempts to follow the actors, such as the delete button, may help researchers catch glimpses of objects in motion, as they (dis)assemble with other (non)human actants and a multitude of practices related to learning and being online. Once actors are identified, the interview continues by looking for configurations of actants and asking: 
How are people and objects brought into proximity with each other? How did they come to be configured this way? What gets "related" to what and how? However, one can begin to appreciate how following actors is a daunting task as more inter-actions and actants emerge. Researchers are faced with the very practical questions of where to begin and when to stop. McLean and Hassard (2004) assert that as a researcher cannot follow actors everywhere, they end up ordering, sorting, and selecting — excluding and including along the way. Such "cutting" of the network becomes an important move by the researcher; an action which Suchman (2007) describes as a practical and analytical act of boundary making.

\section{Heuristic 2: “Listening” for the Invitational Quality of Things}

For phenomenologist Alphonso Lingis $(2004,278)$, the totality of the immediate environment that we inhabit, our lifeworld, is best described as "a milieu—a field of intensive forces, vibrant according to their own inner codes"-in which we are intimately and inextricably caught up in and immersed. Ivan Illich (1996) similarly coins the phrase le milieu technique to refer to the irresistible embrace of the high technology environs we find ourselves dwelling in today. The technological milieu is shaping substantiallyinsinuating itself, habituating us, and simultaneously informing and reinterpreting — how we act in and perceive the world. In order to understand how this occurs, Illich suggests we "listen to what [modern] objects [of technology] say, rather than do" (64). To "hear" what an object of technology might be saying to us, we must enter the realm of lived experience, and orient ourselves to pre-reflective or "pathic" knowing. As pedagogical researcher Max van Manen $(2007,12)$ describes, 
Pathic knowing inheres in the sense and sensuality of our practical actions, in encounters with others and in the ways that our bodies are responsive to the things of our world and to the situations and relations in which we find ourselves. Within the situated, relational, embodied realm of lived space, things and aspects of the environment are perceived or "heard" as invitations. Psychologist J. H. van den Berg $(1972,76)$ illustrates:

We all understand the language of objects....the swimmer enters the water because the water is proving to him in a thousand ways that it is prepared to receive his body. The child digs into the sand because the sand cries out: "dig!" The invitational quality of a thing is always heard in light of our intentionality or indissoluble connection and orientation to the world as child, parent, or teacher. The sandy beach commands the child differently than the watchful parent, or the teenage sibling in the company of friends. The notion of intentionality expresses the phenomenological insight that we do not exist apart from our world, but are always already intimately intertwined, caught up in and tacitly informed by it: "human experience and consciousness necessarily involve some aspect of the world as their object, which, reciprocally, provides the context for the meaning of experience and consciousness" (Seamon 2002). According to Heidegger, the world also discloses itself differently to us depending on the historical epoch we are living in. We currently suffer (and enjoy) the sway of das Gestell (the 'enframing'), the technological way of being: the things of the world tend to appear and speak to us as something to be used and manipulated. Finally, the things of technology are themselves a complex of "instrumental intentionalities" (Ihde 1990). We may thus recognize invitational quality as the pathic or 
pre-reflective interplay between subject and object, the appeal issued from the substantive-hermeneutic tangle of person in his or her world.

Of course, things do not "speak" to us in the same way as people do. Nonetheless, we can see how, having pre-reflectively "heard" and responded to the invitational quality of a thing, we are entered into a primordial rapport with it; we become existentially and hermeneutically engaged. For example, investigating PowerPoint in the classroom, the qualitative researcher may ask: What is PowerPoint's vocative appeal to a student or teacher within the lived space of the classroom? What invitation does PowerPoint make to a teacher as she or he is composing a teaching presentation?

The teacher, sitting in front of her computer screen, launches PowerPoint: "Click to Enter Title, $\bullet$ Click to enter text." Bruno Latour $(1992,232)$ calls this collection of imperative statements "prescriptions" that are encoded in the design of artifacts—nonhumans - that subsequently "utter (silently and continuously)" their implicit intentions "for the benefit of those who are mechanized"-us humans. The new slide invites the teacher to shape his or her knowledge in a particular way, with a title and a set of bullet points. Of course, this is merely an invitation, not an injunction. And yet, thinking back to the PowerPoint presentations you may have experienced over the years, many PowerPoint slidesets do follow this suggested presentational framework. Perhaps yours do too! In seizing hold of PowerPoint as a tool, the teacher is simultaneously enmeshed or caught up in the particular design imperatives, decisions and suggestions embedded in this software. In this way, attending or "listening" to the invitational appeal of things gives aperture to the unique "ongoing horizon of meaning and action" (Introna 2005, 
para. 7) a digital technology may unfold in the context of our teaching and learning worlds.

\section{Heuristic 3: Discerning the Spectrum of Human-Technology Relations}

Ihde (1990), in his study of technics, reveals four types of human-technology relations: embodiment, hermeneutic, alterity and background. Embodiment relations occur when a technological artefact is "incorporated" as part of our bodily experience, becoming an extension of our corporeal self. Automobiles, pencils, and videogame controllers all fall easily in this relational category. We experience the world directly through and with them: technology is the medium through which we prereflectively apprehend and experience the world, transforming our perceptual and bodily senses as well as our abilities. Hermeneutic relations are occasioned when the technology itself is interpreted or 'read' for meaning. We read a thermometer, a map, a book. Thus, to enter into hermeneutic relation with a technology, I must learn its unique language. Ihde names a third focal relation we find ourselves engaged in with technology—alterity. Alterity relations occur when a technological artefact is experienced as quasi-other or anthropomorphically. We may recognize this kind of relation in the intimate bond some develop with their cars or even their iPods, giving them names, perhaps speaking to them with affection. Finally, we also enjoy background relations with technologies, where they function transparently and essentially unnoticed in the "disappeared", taken-for-granted background that is our lifeworld. We have such a relation with today's heating, electrical, and communication systems, for example.

While Ihde's (1990) set of human-technology relations is neither exhaustive nor mutually exclusive, his categories serve to alert us to some of the multiple ways we 
engage technologies everyday. Once more, consider PowerPoint in the classroom. We may discern several of these relational moments. The teacher usually takes up two significant but very different embodiment relations with PowerPoint: (1) in composing a presentation through the PowerPoint software application on a computer, and (2) later in presenting the composed PowerPoint presentation, using computer and data projector. In both cases, we may also discern different ways of being existentially conditioned by the particular PowerPoint configuration. The software script invites the teacher differently than the finished presentation in the context of the classroom.

Hermeneutically, the teacher composing a PowerPoint presentation must learn to read (and write in) the language of the PowerPoint software interface: menus, toolbars and templates, keyboard, screen and mouse. The teacher as presenter also reads (both literally and figuratively) and interprets for students each PowerPoint slide. Thus, the teacher engages PowerPoint hermeneutically as well as existentially. Students too 'read' the PowerPoint slides: their relationship with PowerPoint as student-listeners or studentaudience appears primarily hermeneutic. Nonetheless, there are also compelling existential implications for students. Without hesitation, students turn expectantly to each new slide. Before they have begun to grasp the meaning of the slide, the slide's radiance has already drawn and captured the students' gaze. That is why Merleau-Ponty (1962) says perception is unconscious: in the instant of the moment, we see things before we think them. The PowerPoint image has seen us before we have really seen (understood) it, so to speak.

Alterity relations occur less frequently with PowerPoint, than with a treasured old car or an intelligent robo-dog. On the other hand, if we understand alterity as a reflection 
of our relational intimacies and entanglements with technology, we may notice how PowerPoint and its machinery exercise a potent hold over some teachers. Even as a teacher takes possession of the PowerPoint software, and comes to rely on it in his or her teaching practice, he or she is simultaneously interned to its familiar regime, initiated into and held by its horizon of possibilities, to the particular world disclosed in, with and through this technology. Witness the young college instructor who "cannot teach without PowerPoint", or the teacher who, on the occasion of a brief technical glitch with her laptop humorously remarks, "If PowerPoint crashes, my IQ will drop 20 points." On the one hand, "as technology becomes portable, pervasive, reliable, flexible, and increasingly personalized, so our tools become more and more a part of who and what we are" (Clark 2003, 10). Our corporeal involvements with technologies become less and less separable from who we are or might be as "naked" selves. On the other hand, the more intimately we embrace and become intertwined with a technology, the more vulnerable we are to its breakdowns, to it responding unexpectedly Other-wise than our desire.

Finally, while we most often take up focal—embodiment and hermeneuticrelations with PowerPoint, on occasion background relations also seem to occur. For example, the PowerPoint slide may at times disappear into the background of a classroom discussion, only to suddenly erupt into focus again with a bouncing screensaver.

\section{Heuristic 4: Recognizing the Amplification/Reduction Structure of Human-}

\section{Technology Relations}

Regardless of the type of relation we engage with a technology, Ihde has shown that amplification / reduction is a basic experiential structure of all human-technology relations. By way of example, he describes a dentist's use of a sickle probe, the small 
metal rod with an appointed tip, intended to detect irregularities in a tooth that a finger alone could not sense:

But at the same time that the probe extends and amplifies, it reduces another dimension of the tooth experience. With my finger I sensed the warmth of the tooth, its wetness, etc. aspects which I did not get through the probe at all. The probe, precisely in giving me a finer discrimination related to the micro-features, 'forgot' or reduced the full range of other features sensed with my finger's touch. (Ihde 1979, 21)

Thus, it is important to ask not only what a given technology enhances, but also what it simultaneously reduces or diminishes both experientially and hermeneutically. Consider another example from the classroom: the calculator. What does a calculator amplify? What does it reduce? A calculator amplifies or extends a student's ability to perform mathematical calculations. The student no longer needs to struggle to recall basic addition facts or timetables, nor the algorithms for performing various mathematic functions. The calculator "remembers" all these facts and methods. The student needs only to accurately communicate the mathematical problem to the calculator and press the Enter key. The student can get on with higher-level understandings without being caught in the drudgery of long division calculations or complex formulae.

At the same time, over-stepping or transgressing the previous requirement to recall addition facts or multiplication tables, and the need to perform mathematical procedures such as long division 'by hand', certain numeracy skills begin to atrophy. When such skills are seldom practiced, they are reduced or weakened rather than enhanced or strengthened. The memory of the multiplication tables is slowly forgotten 
like old phone numbers, and the method of long division fades from memory. Of course, educators may decide that such abilities are now essentially obsolete, and thus are willing to allow such basic skills, like numeracy, to attenuate in service of others. A similar observation might be made with handwriting relative to keyboarding, for example. Thus, if numeracy is still deemed to be an important skill, teachers may decide to use calculators more judiciously or to provide practice opportunities elsewhere. Regardless, it is important to recognize that all technologies exhibit this amplification-reduction structure. Here, the McLuhans' (1988) laws of media may prove a particularly helpful tool.

\section{Heuristic 5: Applying the Laws of Media}

Marshall and Eric McLuhan propose four Laws of Media as a way to reveal the totality of individual and socio-cultural effects of a particular media or technology. They explicitly describe these laws as encapsulating and simplifying the efforts of phenomenologists like Heidegger. The laws of media consist of four questions that may be posed of any technology or medium:

-What does [this technology or medium] enhance or intensify?

- What does it render obsolete or displace?

- What does it retrieve that was previously obsolesced?

-What does it produce or become when pressed to an extreme? (McLuhan and McLuhan 1988, 7)

The responses to these questions are visually constructed as a tetrad held in a complex set of poetic tensions. The tetrad intends to focus attention on dynamic "situations that are still in process, situations that are restructuring new perceptions and shaping new 
environments, even while they are restructuring old ones" (McLuhan and McLuhan 1988, 116). Thus the tetrad indicates simultaneous (not sequential) effects. In composing a tetrad, it is helpful to reflect on the more extreme examples-both positive and negative - as well as on the more mundane of a technology's uses, in an effort to tease out unusual textures and the hidden trends. The explicit purpose is to gain insight into how a given technology both enhances and disrupts, and ultimately reshapes current practices in often unexpected ways. An example of a tetrad for PowerPoint is given below (Figure 1).

[Insert Figure 1. PowerPoint Tetrad here]

The tetrad encourages viewing a technology-in-use as a unique and significant agent enhancing, informing and reshaping the complex ecology of the human lifeworld in multiple particularized ways.

\section{Heuristic 6: Studying Breakdowns and Accidents}

Latour (2005) writes that much of the ANT scholar's fieldwork is to multiply the occasions of momentary visibility of objects. One such strategy is to study accidents and breakdowns in order to reveal some of the intimate alliances knitting people and things together in everyday practices. Taking a closer look at these alliances facilitates examination of "how things are normalised and hence are made "inevitable"" (Singleton 2005, 784); important work for qualitative researchers.

The over-riding assumption of self-employed workers in the study on worklearning practices in online communities is that all the people in a particular online community are engaged in the same kind of work. Why else would they be in this space? This assumption binds actants together. It "normalizes" the notion of an online 
"collective". However, an array of actants continually challenged this assumption and created passages that both opened up and closed down online spaces. I turn to an anecdote from the data:

Nancy is a new member in Dorothy's online community of home-based daycare providers, a close-knit group of women. Some members have recently started to have face-to-face meetings with the others that live close by. Nancy invites Dorothy over to her house - her workspace - to get some advice. After all, Dorothy has been running a daycare for 12 years and is known as the 'little boss' on the online board. Getting together in person is a recent change in the configuration of this online community, which used to restrict itself to online encounters. Arriving at Nancy's house, Dorothy is taken aback. This isn't a daycare at all. Dorothy is confused. Nancy's comments, questions, and empathetic understandings in the online conversations sounded like they were coming from someone who was running a daycare. Dorothy reports this fabrication to the woman who owns the board and the membership list is quickly culled. Calling it 'housecleaning', the online space is made private. A new password is set up and only given to the core group of 40 people. Nancy is purposefully excluded.

This online community has experienced a breakdown. Resetting passwords and a new shorter membership list are examples of how technologies (objects) re-established boundaries. As an actant, the password was used purposefully to exclude participants and in so doing a stronger sense of inclusion, belonging, and connection between those remaining was created. Something new started circulating through this network. A reaffirming of what "should" be was mobilized: a reinforced belief among the 40 people that, "WE are legitimate daycare providers". 


\section{Heuristic 7: Untangling Tensions}

In the above anecdote, the sense of being infiltrated by an outsider had ripple effects throughout the network and led to a stabilization (an attempt to order and generate stable and predictable arrangements). Purposefully excluding some cuts the network and shapes a new configuration - there is a re-ordering. Latour (2005) argues the importance of attending to what networks become stabilized, given that a "normal" state of any actornetwork is one of change.

It would seem that both stabilizations and disruptions are a necessary tension. As a qualitative researcher, paying attention to the efforts of entities and circulations to stabilize and disrupt is another way to catch a glimpse of objects in inter-action and helps to map many tensions and contradictions: Latour's (2005) "matters of concern". Both stabilizations and disruptions are a necessary tension. Singleton $(2005,775)$ suggests that tensions are productive because they "expose the fluidity of boundaries and work against the stability of categories".

For example, one tension highlighted in Dorothy's anecdote is about belonging: Who belongs in a particular online community and who makes this determination? Rather than closing ranks, another stabilization might have been to open up the space and invite in people who had a more peripheral interest in home-based daycares. Yet, an unsettled space was created by the unexpected contradiction when the Nancy-as-daycare-provideronline network intersected with the Nancy-as-pseudo-daycare-provider-offline network. This space and its new partial connections could not be sustained. Issues of authenticity and trust were strong: Who are the others in your community and how do you discern this in an online space? Both the opaqueness and transparency of web technologies can be 
enlisted to reveal, hide, and alter the other. Objects, such as passwords and membership lists extend a human's ability to verify and gate keep. Untangling contradictions, such as these, can perhaps help to identify tensions in the way human and non-human entities become intertwined, particularly within the materiality of an online "community".

\section{Heuristic 8: Construct Co(a)gents}

Michael (2004) describes a co(a)gent as humans and nonhumans operating together to produce patterns of connection. He adds that the co(a)gent is an analytical fabrication that adds value when it illuminates otherwise hidden processes. To use this heuristic to interview objects, qualitative researchers might conceptualize different co(a)gents and then trace the patterns of connections that make up these different co(a)agents. One example Michael (2000) studies is the "couch potato": a co(a)gent comprised of person, sofa, TV, and remote control. Using this construction he then asks, "What is the relationship between body, agency and technology that the remote control mediates?" (96). Other interview questions to catch glimpses of the remote control in inter-action include: When does the couch potato make its appearance? In what ways is this routine? What would happen if one of the constituent parts (i.e., the remote control or the sofa) disappeared?

In a similar manner, phenomenological understanding supercedes the classical separation of subject and object. The lifeworld is characterized by the transpermeation (Rosen 2006) and intermingling of subject and objects through the "reciprocal insertion and intertwining of one in the other" (Merleau-Ponty 1968, 138). Actor-NetworkTheorists signal this human-technology relation with hyphens where human and technologies may be commutatively switched back and forth, recognizing the 
"ambiguous interplay of subject and object in the lifeworld" (Rosen 2006, 24) as well as symmetry of agency. Post-phenomenologist Ihde (2004) indicates this co-relational intertwining of human and technology with varying hyphens and brackets designating different types of relation (rather than equality of agency).

\section{Objects interviewed}

So what did we learn by our attempts to "interview" objects? Using conceptual tools from ANT in order to "interview" objects in a study of informal work-learning in online communities, several implications for educators came to light. Full findings and implications are elaborated in Thompson (2010a, 2010b). Briefly, first, although the technologies used by participants in this study were not complicated, the enactment of learning comprised new objects, relations, and mobilization of practices — with some of this "work" quite invisible. Law $(2007,126)$ points to the tensions within learning practices, commenting that if practices do cohere as learning practices, this is only temporary, and paradoxically, if practices look streamlined then it is because the bits that do not fit and the choreography that holds it all together is not visible or understood. Second, despite the wide-open nature of the Web, there are differences in the way people leverage online learning opportunities. In ANT parlance, "performances are difficult to put on unless they build on the networks that are already in place" (Law and Singleton $2000,4)$. In other words, networks cannot be plucked out of thin air. And so questions of access and competence are significant. It may be helpful for educators and workerlearners to get a better sense of how the presence or absence of certain actor-networks play out in the enactment of richer or more impoverished work-learning practices. Third, adult educators may risk underestimating the critical information and digital literacies 
required to participate in these informal online spaces if they do not attend to the complexities of these very socio-material practices; complexities which become more apparent by unravelling the many actor-networks in play.

From a phenomenological perspective, "interviewing" PowerPoint, that is, catching glimpses of the software presentation tool in teachers' and students' lifeworlds, yielded several important insights regarding the "use" of educational technologies (Adams 2006, 2008, 2010). For example, PowerPoint sponsors a prescribed (default) framework for staging knowledge: headings and bullet points for teachers to "talk to." This scaffolding tacitly informs how some teachers visualize and subsequently present their knowing in the lived space of the classroom. The PowerPoint slideshow, regardless of the kind of knowledge it frames, exercises a powerful sway over the teacher in moments of teaching, at times appearing as impenetrable obstacle, rather than as generative support to the teacher pursuing his or her sense of pedagogical tact. In this way, the continued promotion of digital media technologies as neutral agents - $\mathrm{a}$ foundational belief or "posit" of our current ontological epoch-imperils the normative project of pedagogy by concealing the instrumental constructs they materialize. These understandings also point back to software architects. What explicit or implicit theory of teaching and learning informed the design of the given technology? How do teachers and students experience teaching and learning in and with these technologies, particularly given technologies are often "unfaithful" (Latour, 1988) to their creators, and thus inevitably produce unexpected effects beyond the educational aims intended? Finally, educators are perhaps best served by living more critically and reflectively with the 
digital technologies they choose to adopt, attending not only to what they do, but what they may undo; to what they say and what they cannot say.

\section{Conclusion}

Latour (1992) worries about the unnoticed "missing masses": the non-humans that are everywhere, strongly social and moral, but nevertheless overlooked by researchers. The commonsense, "tool" view of technology has incorrectly allocated all agency to human beings, rendering things inconsequential and thus invisible to researchers. Within education inquiry, this results in a black boxing of the role of the environment and privileging the role of the human subject (Waltz 2004). We must now strive toward a more inclusive posthuman perspective that "gives artefacts a voice", especially in technology-supported learning environments. Articulating our intimate, co-constitutive involvements "with things may enlarge our understanding of what education is, how it occurs, and how to make it more powerful and equitable" (Waltz 2004, 172). Along these lines, Selwyn (2010) calls for a "critical" study of educational technology by "developing objective and realistic accounts of technology us in situ", and via these everyday contexts, unearthing the "social conflicts and politics that underpin the use of technology in educational settings" (p. 65). We believe "interviewing" objects is one approach to contributing to this collection of much-needed accounts of technology use in education.

In this article we argue the importance of including technologies-in-use as key qualitative research participants when studying today’s digitally-enhanced learning environments. In so doing, researchers may strive towards a broader perspective that encircles the "voice" of artefacts - from the most mundane to the exotic (Michael 2000) — and thus begin to disclose their material agency in co-constituting teaching- 
learning worlds. We have collected a set of heuristics and insights to assist qualitative researchers in giving educational artefacts a voice. Although we have found this particular collection of heuristics helpful in our own phenomenological and ANT research endeavours, there are other methodological possibilities emanating from other object-inclusive perspectives such as complexity theory or activity theory. In setting out our own tool-box collection, we hope to create an opening for other researchers (especially those who have not yet delved into this facet of human-technology research) to directly explore the co-constitutive relationship between humans and technologies. Finally, the heuristics presented here were derived from two different theoretical traditions, and thus may not all be applicable in a single study. Nonetheless, some philosophers of technology have begun to uncover numerous points of overlap between the two approaches.

Given the proliferation of distributed systems in which ICTs collaborate alongside individuals, questions are increasingly asked about the role of information technologies in our lives (Levy, 2007). Latour (2005) cautions that all too quickly matters of concern become solidified into matters of fact: backgrounded, black boxed, and locked down. Introna draws on both phenomenology and Latour to put forward disclosive ethics as a way to make the morality of technology visible. Disclosive ethics involves attending to the "way in which seemingly pragmatic attempts at closing and enclosing connect together to deliver particular social orders that (ex)includes some and not others" (2007, 16). Interviewing objects brings technologies-in-use out of the background and into critical inquiry, and thus enables educational researchers to examine such political and ethical questions. 


\section{References}

Adams, Catherine. 2006. PowerPoint, habits of mind, and classroom culture. Journal of Curriculum Studies 38, no. 4: 389 - 411.

Adams, Catherine. 2008. PowerPoint's pedagogy. Phenomenology and Practice 2, no. 1: 63-79.

Adams, Catherine. Forthcoming, 2010. Teachers building dwelling thinking with slideware. The Indo-Pacific Journal of Phenomenology 10, no. 2.

Adams, Catherine, and Max van Manen. 2008. Phenomenology. In The SAGE Encyclopedia of Qualitative Research Methods, ed. L. Givens, 614 - 619. Thousand Oaks: Sage.

Benso, Silvia. 2000. The face of things: a different side of ethics. Albany, NY: State University of New York Press.

Boyd, Danah. 2006. G/localization: When global information and local interaction collide. Paper presented at the O'Reilly Emerging Technology Conference. http://www.danad.org/papers.Etech2006.html

Callon, Michel. 1987. Society in the making: The study of technology as a tool for sociological analysis. In The social construction of technological systems: New directions in the sociology and history of technology, ed. W. E. Bijker, T. P. Hughes, and T. J. Pinch, 83-103). Cambridge, MA: MIT Press.

Clark, Andy. 2003. Natural born cyborgs: Mind, technologies, and the future of human intelligence. Oxford: Oxford University Press. 
Crease, Robert, Don Ihde, Casper B. Jensen, and Evan Selinger. 2003. Interview with Bruno Latour. In Chasing technoscience: matrix of materiality, ed. D. Ihde and E. Selinger, 15-26. Bloomington, IN: Indiana University Press.

Hansen, Mark. 2006. Media theory. Theory, Culture \& Society 23, no. 2-3: 297-306.

Harman, Graham. 2007. The importance of Bruno Latour for philosophy. Cultural Studies Review 13, no. 1: 31-49.

Harman, Graham. 2009. Prince of networks: Bruno Latour and metaphysics. Melbourne, Australia: re.press.

Heidegger, Martin. 1962. Being and time. New York: Harper and Row. Heuristic Methods. n.d. In MindTools. http://www.mindtools.com/pages/article/newTMC_79.htm

Ihde, Don. 1979. Technics and praxis. Dordrecht, Holland: D. Reidel Publishing. Ihde, Don. 1990. Technology and the lifeworld: from garden to earth. Bloomington: Indiana University Press.

Ihde, Don. 2004. Has the philosophy of technology arrived? A state-of-the-art review. Philosophy of Science, January 2004: 117-131.

Illich, Ivan. 1996. Philosophy ... artifacts ... friendship — and the history of the gaze. In Philosophy of Technology: Proceedings of the American Catholic Philosophical Association, 70, ed. T.-A. Druart, 61-82. Washington, DC: National Office of the American Catholic Philosophical Association, Catholic University of America.

Introna, Lucas. 2005. Phenomenological approaches to ethics and information technology. In The Stanford Encyclopedia of Philosophy. 
http://plato.stanford.edu.login.ezproxy.library.ualberta.ca/entries/ethics-itphenomenology/

Introna, Lucas. 2007. Maintaining the reversibility of foldings: Making the ethics (politics) of information technology visible. Ethics and Information Technology, 9: $11-25$.

Jager, Bernd. 1985. Body, house, and city: the intertwinings of embodiment, inhabitation and civilization. In Dwelling, Place, and Environment: Toward a Phenomenology of Person and World, ed. D. Seamon \& R. Mugerauer, 215-225. Dordrecht: Martinus Nijhoff.

Latour, Bruno. 1988. The Pasteurization of France. Trans. A. Sheridan and J. Law. Cambridge, MA: Harvard University Press.

Latour, Bruno. 1992. Where are the missing masses? A sociology of a few mundane artefacts. In Shaping Technology/Building Society: Studies in sociotechnical change, ed. W. E. Bijker \& J. Law, 225-258. Cambridge, MA: MIT Press.

Latour, Bruno. 1993. We have never been modern. Trans. C. Porter. Cambridge, MA: Harvard University Press.

Latour, Bruno. 1999. Pandora's Hope: Essays on the Reality of Science Studies. Cambridge, Mass: Harvard University Press.

Latour, Bruno. 2005. Reassembling the social: An introduction to actor-network theory. Oxford: Oxford University Press.

Law, John. 2007. Pinboards and books: Juxtaposing, learning, and materiality. In Education and Technology: Critical perspectives, possible futures, ed. D. W. Kritt and L. T. Winegar, 125-149. Lanham, MD: Lexington Books. 
Law, John. 2008. On sociology and STS. The Sociological Review 56, no. 4: 623-649.

Law, John, and Vicky Singleton. 2000. This is not an object. http://www.lancs.ac.uk/fass/centres/css/

Leander, Kevin M., and Jason F. Lovvorn. 2006. Literacy networks: Following the circulation of texts, bodies, and objects in the schooling and online gaming of youth. Cognition and Instruction 24, no. 3: 291-340.

Levy, David M. 2007. Information, silence, and sanctuary. Ethics and Information Technology 9, no. 4: 233-236.

Lingis, Alphonso. 2004. Trust. Minneapolis: University of Minnesota.

McLean, Christine, and John Hassard. 2004. Symmetrical absence/symmetrical absurdity: Critical notes on the production of actor-network accounts. Journal of Management Studies 41, no. 3: 493-519.

McLuhan, Marshall, and Eric McLuhan. 1988. Laws of media: the new science. Toronto, ON: University of Toronto Press.

Merleau-Ponty, Maurice. 1962. Phenomenology of perception. Trans. C. Smith. New York: Routledge.

Merleau-Ponty, Maurice. 1968. The visible and the invisible. Trans. A. Lingis. Evanston: Northwestern University Press.

Michael, Mike. 2000. Reconnecting culture, technology and nature: From society to heterogeneity. London: Routledge.

Michael, Mike. 2004. On making data social: Heterogeneity in sociological practice. Qualitative Research 4, no. 1: 5-23. 
Mitcham, Carl. 1994. Thinking through technology: the path between engineering and philosophy. Chicago: The University of Chicago Press.

Mol, Annemarie. 2002. The body multiple: Ontology in medical practice. London: Duke University Press.

Neyland, David. 2006. Dismissed content and discontent: An analysis of the strategic aspects of actor-network theory. Science, Technology \& Human Values 31, no. 1: 29-51.

Rosen, Steven M. 2006. Topologies of the flesh: a multidimensional exploration of the lifeworld. Athens, OH, USA: Ohio University Press.

Singleton, Vicky. 2005. The promise of public health: Vulnerable policy and lazy citizens. Environment and Planning D: Space and Society 23, no. 5: 771-786.

Seamon, David. 2002. Phenomenology, place, environment, and architecture: a review of the literature. http://www.phenomenologyonline.com/articles/seamon1.html.

Selwyn, N. (2010). Looking beyong learning: notes towards the critical study of educational technology. Journal of Computer Assisted Learning, 26(1), 65-73.

Suchman, Lucy. A. 2007. Human-machine reconfigurations: Plans and situated actions ( $2^{\text {nd }}$ ed.). Cambridge, England: Cambridge University Press.

Thompson, Terrie Lynn. 2010a. (Re/Dis)assembling learning practices online with fluid objects and spaces. Manuscript submitted for publication.

Thompson, Terrie Lynn. 2010b. Who's taming who? Tensions between people and technologies in cyberspace communities. In Proceedings of the 7th International Conference on Networked Learning 2010, ed. L. Dirckinck-Holmfeld, V. 
Hodgson, C. Jones, M. de Laat, D. McConnell, and T. Ryberg. http://www.lancs.ac.uk/fss/organisations/netlc/past/nlc2010/index.htm

Van den Berg, Jan H. 1972. A different existence. Pittsburgh: Duquesne University Press.

Van Manen, Max. 1997. Researching lived experience: Human science for an action sensitive pedagogy, $2^{\text {nd }}$ edition. London, ON: The Althouse Press.

Van Manen, Max. 2002. The tact of teaching: the meaning of pedagogical thoughtfulness. London, ON: The Althouse Press.

Van Manen, Max. 2007. The phenomenology of practice, Phenomenology \& Practice 1, no. 1: $11-30$.

Van Manen, Max, and Catherine Adams. 2009. The phenomenology of space in writing online. Educational Philosophy and Theory 41, no. 1: 10-21.

Van Manen, Max, and Catherine Adams. 2010. Qualitative research: Phenomenology. In International Encyclopedia of Education, Volume 6, ed. E. Baker, P. Peterson and B. McGaw, 449-455. Oxford, UK: Elsevier.

Verbeek, Peter-Paul. 2005. What things do: philosophical reflections on technology, agency, and design. Cambridge, Mass: MIT Press.

Waltz, Scott B. (2004). Giving artifacts a voice? Bringing into account technology in educational analysis. Educational Theory 54, no. 2: 157-172. 